\title{
Consideraciones sobre la ciudad en época visigoda
}

\author{
Lauro Olmo Enciso*
}

\section{A modo de introducción o declaración de intenciones}

Un análisis sobre la ciudad debe partir y tomar en cuenta la sociedad y el marco de relaciones que en ella se desarrollan. La aceptación de esta premisa es fundamental, desde la perspectiva que anima este trabajo, para desarrollar un análisis de la ciudad en época visigoda.

La investigación arqueológica efectuada en los últimos años, así como las propias fuentes escritas, proporcionan datos suficientes para defender la diversidad cultural de la península ibérica durante la época visigoda (OLMO ENCISO, 1992). Esta diversidad cultural es un elemento de gran importancia a la hora de acometer el análisis global de la ciudad de este periodo, dado que afecta a las características de las ciudades que se asientan en los diferentes territorios peninsulares (OLMO ENCISO, 1990-97: 265).

La naturaleza, estructura y desarrollo del Estado visigodo, así como las características del conflicto social que se desarrolla en la península ibérica en ese periodo, constituyen los otros elementos fundamentales a tener en cuenta. El reino visigodo no es un ente homogéneo sino más bien al contrario, está definido por diferentes fases, como consecuencia del citado conflicto que se desarrolla, fundamentalmente, entre monarquía y aristocracia.
Por tanto, sociedad, naturaleza del estado, diversidad cultural, territorio...... constituyen las premisas fundamentales a la hora de plantear un análisis riguroso sobre la ciudad.

Quiero comenzar exponiendo qué es lo que entiendo por ciudad, ya que ello resume todo el proceso argumental que a continuación se va a exponer. La ciudad es un centro administrativo, político, ideológico y económico, expresión espacial de una sociedad compleja y que, por tanto, reflejará en su interior y en su territorio, el proceso de transformaciones que afectan a dicha sociedad (OLMO ENCISO, 1995: 218).

Por tanto, el análisis de la ciudad en época visigoda, debe realizarse teniendo en cuenta el proceso de transformaciones que se producen en el Estado toledano como consecuencia de las dinámicas generadas por la tensión resultante de la defensa de diferentes modelos de sociedad. De esta forma, el hecho de que se observen dos fases en el desarrollo del Estado toledano, constituye un fenómeno capital a la hora de analizar la cuestión urbana de este periodo. La documentación arqueológica obtenida en algunos de los grandes centros urbanos de la época objeto de excavación en los últimos años, que a continuación se analizarán, permite igualmente defender la existencia en estas ciudades de dos fases. La primera de estas reflejaría un renacimiento de la importancia de la ciudad y hay que situarla entre la segunda

* Universidad de Alcalá. Departamento de Historia y Filosofía 
mitad del VI y primeras décadas del VII, relacionada con el fortalecimiento de las estructuras del Estado. La segunda de estas fases correspondería a una desestructuración de la trama urbana, que debe conectarse con la crisis del Estado toledano. Este paisaje urbano diferente al que definía la ciudad de la segunda mitad del $\mathrm{VI}$ es el que encontrarán los árabes. Esta estructura urbana dinámica que, al igual que en otros periodos históricos define, por ahora, a alguna de las mayores ciudades de época visigoda, ofrece una nueva perspectiva de análisis de la ciudad integrada en el desarrollo del proceso histórico de la época y, por tanto, opuesta a visiones rígidas del fenómeno urbano de este periodo.

\section{La ciudad durante la fase de formación y consolidación del estado visigodo}

Para la época de fundación y consolidación del Reino visigodo de Toledo, la interpretación de los diversos tipos de fuentes, entre las que cobran especial relevancia los resultados de intervenciones arqueológicas recientes, ofrece una visión que configura un tipo de ciudad, definitorio de esta fase del Estado visigodo, que además revela cómo para esa época la base de la estructuracion de la sociedad y del Estado es claramente la ciudad.

En este sentido, hay que detenerse en comprobar cómo la documentación procedente de las fuentes escritas contiene datos que testimonian la existencia de un proceso de transformación de las instituciones urbanas que se desarrollará a lo largo del siglo VI en la península ibérica. Comenzaremos con uno de los temas más debatidos como es el de la función de los curiales en estos centros urbanos. Sabemos que a principios del siglo $\mathrm{VI}$, tal y como nos transmite Casiodoro (Variae, V, 39, 2) estos curiales habían perdido sus funciones de gobierno así como sus atribuciones fiscales, sin que esto implique su desaparición, ya que su existencia se documenta hasta el reinado de Chindasvinto (L.V., V, 4, 19). En este sentido, un fenómeno similar se produce en el Imperio Bizantino donde parece que, ya para mediados del siglo $\mathrm{VI}$, estos curiales habían perdido su importan- cia y su papel en el 550 d.n.e., tal y como transmite Juan de Lido (De Magistratibus), pudiéndose seguir rastros de su existencia hasta el siglo VII, tanto en el Imperio Bizantino como en la península itálica (WHITTOW, 1990). Sin embargo, y dentro del estudio de las dinámicas sociales de este periodo, comprobaremos cómo la existencia de una élite urbana que asume las funciones de gobierno y las atribuciones fiscales es algo que está demostrado a lo largo de todo el proceso de formación y consolidación del Estado visigodo. Definiendo mejor la naturaleza de esta élite se comprueba como las figuras claves de la vida urbana fueron el obispo, los miembros de la aristocracia fundiaria y los oficiales con responsabilidades fiscales y judiciales, describiendo, por tanto, un proceso similar al de las otras áreas mediterráneas. Estos testimonios sobre las nuevas realidades, que afectan a la administración de la ciudad con la asunción de las funciones fiscales y de administración urbana por parte de una élite religiosa o pública, constituyen así mismo un reflejo del proceso de transformaciones y conflicto social que se desarrollará a lo largo de este siglo $\mathrm{VI}$ y el posterior. Este proceso nos ofrece, en el caso que aquí nos ocupa, un paisaje urbano menos sofisticado que en épocas anteriores y, por tanto, más polarizado socialmente sobre el que la investigación arqueológica está aportando pruebas fundamentales en alguna de las ciudades de época visigoda.

Acabo de mencionar la participación en el gobierno de las ciudades del obispo y el clero, así como de oficiales dependientes de la administración central. Ello nos ilustra sobre una característica de las ciudades en el momento de consolidación del Estado visigodo, la presencia del Comes Ciuitatis y del obispo como personajes determinantes del gobierno de estas. El Comes Ciuitatis como máximo magistrado de la ciudad y su territorio durante el reinado de Leovigildo, va a estar ampliamente presente en casi todas las ciudades (GARCIA MORENO, 1993), donde tendrá una serie de subordinados: Vicarius, ludex loci, Defensor ciuitatis. El papel del obispo en el gobierno de las ciudades será determinante y se situará en pie de igualdad con el mencionado Comes. Esta trascendencia del papel del obispo en la vida y administra- 
ción urbana que es evidente bajo Leovigildo, se acrecentará e institucionalizará, a partir de Recaredo (L.V., XII, I,2) con una serie de prerrogativas, entre las que destaca la potestad de nombramiento de cargos menores como el Numerarius o el Defensor Ciuitatis, tal y como se comprueba de la propia legislación dictada bajo dicho rey, así como de otros documentos entre los que hay que destacar la Epistola de fisci barcinonensi, valioso ejemplo de delegación por parte del Estado del sistema de recaudación de impuestos. Estas noticias reflejan el intento de Leovigildo por crear un Estado centralizado basado en el control de todo el sistema fiscal por parte de una administración pública y en detrimento del creciente poder de la Iglesia y la aristocracia. Creo que, formando parte de esta política de afirmación del poder del Estado, es donde hay que situar la intención de Leovigildo de cohesionar ideológicamente a la sociedad apoyándose y favoreciendo a la Iglesia arriana, en detrimento del poder de la Iglesia católica. En este sentido, conviene no olvidar que hasta ese momento no tenemos ninguna noticia que refleje conflictos entre católicos y arrianos, y asímismo cómo la jerarquía católica está formada por miembros que proceden fundamentalmente de la aristocracia fundiaria. La rebelión de Hermenegildo, una rebelión protagonizada por esta aristocracia y jerarquía católica, que se servirán a su vez del catolicismo como factor de cohesión ideológica, proporciona un valioso testimonio de la oposición de un grupo fundamental de la clase dirigente ante la amenaza, contraria a sus intereses, de un Estado basado en una administración centralizada y en el control fiscal. Esta rebelión, a la que habrá que añadir las que las fuentes nos transmiten para los primeros momentos del reinado de Leovigildo, refleja el conflicto entre un Estado basado en el control del sistema tributario todavía dominante, y los defensores de un modelo de sociedad feudal, a la que habría que añadir la oposición a ambos que va a ejercer el campesinado (WICKHAM, 1984: 15-26; 1988: 189-193; 1989; |40-141; OLMO ENCISO, 1988: 253-255, 655-666; 1992: 196; 1995: 217; 1990-97: 267). El reconocimiento por Recaredo del protagonismo social de la Iglesia católica III Concilio de Toledo- así como del papel de los obispos en el gobierno de las ciudades y la delegación que en parte de ellos hace del sistema de recaudación fiscal, significa el reconocimiento de la necesidad de incorporar a la propia estructura del Estado a la Iglesia católica que si bien en esta primera fase participará en ella se convertirá, posteriormente, en la segunda en uno de los elementos fundamentales para entender la desestructuración del Estado visigodo.

Durante esta fase de formación y consolidación del Estado visigodo, que se desarrolla en la segunda mitad del siglo VI, o más concretamente en su último tercio, se comprueba cómo se asiste a una recuperación de la política edilicia y urbanística, lo cual proporciona un dato de gran interés a la hora de defender el papel de las ciudades como centros fundamentales de la estructura social de la época. Esta recuperación urbana va a estar a cargo exclusivamente de la Iglesia y del naciente Estado visigodo.

\section{Iglesia y ciudad}

La importancia que la cristianización posee, como fenómeno religioso e ideológico, para analizar tanto la sociedad bajoimperial como la del periodo que nos ocupa, ha tenido gran incidencia en los análisis sobre la realidad urbana de la época, como ya se ha mencionado anteriormente. Esta relevancia de la Iglesia católica y de las actuaciones de su jerarquía en el planeamiento urbano de la época constituye un elemento fundamental para entender el papel trascendente de esta institución en la sociedad del periodo, pero no representa el único elemento característico de la ciudad como veremos más adelante. De hecho, esta importancia debe ser analizada atendiendo al lugar que ocupa dentro del proceso de transformaciones que se desarrollan en esta época y, por tanto, matizada como concepto y contextualizada socialmente.

A lo largo del siglo $\mathrm{VI}$ poseemos testimonios, al igual que para otras áreas del Mediterráneo, acerca de la actividad edilicia de la iglesia en el entramado urbano, apreciándose un sensible aumento de ésta en la segunda mitad del siglo. Fruto de esta actividad de inicios de 
la centuria tendríamos, por el momento, constatados tanto por las fuentes arqueológicas como por las escritas, los casos de Valencia, Tarragona, Barcelona y Mérida.

En Valencia, a mediados del siglo $\mathrm{Vl}$, una inscripción documenta la construccción de nuevos edificios religiosos, y reconstrucción de los antiguos, efectuadas por el obispo Justiniano (VIVES, 1969: 85, $n^{\circ}$ 279). Así mismo, otra inscripción nos documenta la continuidad de esta política edilicia en el siglo VII por parte del obispo Anesio (VIVES, 1969: 123, n 356; SORIANO SANCHEZ, 1995: 134). La arqueología ha documentado la existencia de todo un conjunto de edificaciones religiosas que se relacionan con un complejo episcopal, descubierto en la zona del antiguo Foro romano, donde a partir del siglo $\checkmark$ se configura urbanísticamente dicha área religiosa. Esta la forman un templo de planta de cruz griega fechado en el siglo $\mathrm{V}$, parte de una edificación poligonal del siglo VI interpretada como la catedral, así como los restos de un ábside de herradura que corresponde, posiblemente, a una basilica de tres naves que se relaciona con templos similares de finales del siglo VI (SORIANO SANCHEZ, 1995: 135-139).

La ciudad de Tarragona, donde unas construcciones localizadas en el área del antiguo Foro provincial se interpretan como los restos del conjunto episcopal de inicios del VI, nos ofrece otro ejemplo de esta actividad edilicia con la construcción de la basílica del Anfiteatro en la segunda mitad del siglo $\mathrm{VI}$, dentro de un contexto cultual de veneración y exaltación de mártires (A.A.V.V., 1990: 234-235, 24I).

En la segunda mitad del VI se datan las obras de remodelación de la basílica de Barcelona (GRANADOS, 1995: 125) que deben inscribirse en un fenómeno de creciente importancia de esta ciudad, así como de su obispado, tal y como transmite la ya citada Epistola de fisci barcinonensi.

La ciudad de Mérida proporciona un ejemplo sobre el cual, tánto las fuentes escritas -Vidas de los Santos Padres Emeritenses- como las arqueológicas, ilustran ampliamente acerca de su dinamismo urbano así como de la polí- tica edilicia de los obispos emeritenses, a partir de la segunda mitad del VI, entre los que hay que destacar a Fidel (560-570) y Masona (570-605) (MATEOS, 1992: 57-79; 1995: 239-263; CABALLERO ZOREDA, MATEOS, 1992: 15-4I). Fidel acometerá las restauraciones del palacio episcopal, así como la reedificación de la basilica de Santa Eulalia -extramuros del recinto de la ciudad que, como demuestran las recientes intervenciones arqueológicas, se configurará en el nucleo urbanístico a partir del cual se desarrolle toda una serie de nuevas construcciones (CABALLERO ZOREDA, MATEOS, 1992: 19). Masona ejemplificará el desarrollo y control, por parte de la Iglesia, de una política asistencial en el marco urbano, atestiguada por la construccción de un xenodochium, hospital y albergue para peregrinos, fundado en el 573, recientemente localizado y excavado en las cercanías de Sta. Eulalia (MATEOS, 1992: 68-71). Sin embargo, las recientes intervenciones arqueológicas nos muestran cómo esta política edilicia de la Iglesia, forma parte de todo un proceso de dinamismo urbano en la Mérida visigoda que supone la reocupación de áreas abandonadas en el siglo $\mathrm{V}$, tal y como transmiten los importantes hallazgos en la zona arqueológica de Morería. Estos hallazgos documentan, para esta zona, una primera fase que supone la continuidad del urbanismo de la época bajoimperial, aunque con una progresiva tendencia en las viviendas de nueva planta a ocupar parte de las calles, así como la transformación de las antiguas domus bajoimperiales en "casas de vecinos" comunitarias, que indican para esta zona de la Mérida de época visigoda, un cambio de la estructura habitacional, así como una mayor densidad de población que en las épocas anteriores (ALBA CALZADO, 1997: 293-294, fig. 7). La segunda fase de Morería, en esta época, contempla una amortización de toda esta zona de vivienda, que sugiere un abandono planificado, tal y como documenta el cegado de pozos y el relleno con gran cantidad de escombros y tierra de las zonas próximas a la muralla (ALBA CALZADO, 1997: 294). Esta zona se utilizará como vertedero durante todo el siglo VIII, para posteriormente volver a reocuparse en el siglo IX, en una primera fase de época emiral, con una serie de grandes edificios exentos separados entre sí por un trazado de calles que mantiene la idea 
de un esquema reticular (ALBA CALZADO, 1997: 295, fig. 8).

Por tanto, y para esta época, tal y como puede deducirse de la documentación escrita y arqueológica que poseemos para las ciudades analizadas, puede defenderse la existencia en ellas de un fenómeno de actividad edilicia, por parte de la jerarquía eclesiástica especialmente notable durante la segunda mitad del siglo VI. Este fenómeno debe inscribirse dentro de un proceso de revitalización urbana que se desarrolla en una serie de ciudades en esta segunda mitad del siglo VI, evidente en el caso de Mérida así como en Recópolis y otros descritos por las fuentes escritas.

\section{La participación y presencia del Estado en la ciudad}

Sin embargo, un aspecto novedoso en el que quiero detenerme e incidir, lo constituye frente a lo ya citado sobre la política edilicia de la Iglesia, la participación del Estado en este proceso edilicio y de mejoras en el paisaje urbano. En la época de la constitución del reino de Toledo, se puede comprobar como el Estado, en este caso la monarquía visigoda toledana, se hace cargo y desarrolla una política edilicia, así como de fundación de ciudades -Recópolis, Victoriaco, Ologicus-, que está testimoniando la asunción de una política no asumida ya desde finales de la época bajoimperial por las oligarquías urbanas. Esto conecta con otro de los elementos que se deducen de esta política real de fundación o rehabilitación de ciudades, que caracteriza fundamentalmente la época de Leovigildo y es la importante capacidad de recaudación fiscal que la monarquía toledana poseía en la segunda mitad del siglo VI, es decir, en el momento fundacional del reino. El más que probable éxito en la imposición de un sistema fiscal controlado por el Estado necesario para poner en marcha toda esta actividad, a la que acabo de hacer referencia, está documentado en el pasaje de la Historia Gothorum de Isidoro de Sevilla donde a propósito de Leovigildo nos transmite "Este enriqueció también al fisco y aumentó el erario con la expoliación de los ciudadanos y los despojos de los enemigos". Dentro de esta política de creación de un Estado basado en un sistema fiscal controlado y centralizado hay que incluir el inicio de la acuñación de moneda por parte de este rey. Este contexto es el que ayuda a entender las causas que motivaron y posibilitaron la gran fundación urbana del periodo, la ciudad de Recópolis.

La fundación de Recópolis en el año 578 constituye, por tanto, un claro ejemplo del poder del Estado en el momento de fundación del reino visigodo, así como una expresión material de la ideología del naciente Estado. La parquedad de las fuentes escritas de época visigoda contrasta con la relevancia que estas mismas dan a la fundación de la ciudad, así como las referencias en la documentación de época andalusí y cristiana (OLMO ENCISO, 1995:212). Fundamental es la noticia de Juan de Biclaro, contemporáneo de los acontecimientos, quien transmite en su Chronica dentro de los hechos acaecidos en el año 578 "Liuuigildus rex extinctis undique tyrannis, et pervasoribus Hispaniae superatis sortitus requiem propiam cum plebe resedit civitatem in Celtiberia ex nomine filii condidit, quae Recopolis nuncupatur: quam miro opere et in moenibus et suburbanis adornans privilegia populo novae Urbis instituit" (CAMPOS, 1960: 88).

Las excavaciones arqueológicas en Recópolis nos ofrecen el testimonio de dos fases correspondientes a la época visigoda seguidas de tres fases de época andalusí, correspondientes, a su vez, al periodo emiral entre los siglos VIII y principios del IX. Las dos fases de época visigoda reflejan un ámbito urbano no estático ni homogéneo y, por tanto, sometido a unas dinámicas de transformación conectadas con el proceso de cambios que se desarrollan en la estructura social de la época. La primera de estas fases nos muestra, en el área hasta el momento excavada, la existencia de un plan urbanístico definido por un trazado regular y una jerarquización del espacio urbano. El conjunto de edificaciones palatinas entendidas por su función administrativa y residencial- situado en la zona superior de la ciudad y estructurado alrededor de una plaza cerrada en sus lados Norte y Sur por dos grandes edificios -de 133 mts. de longitud el del lado Norte- de dos plantas, y en su lado Este por 
otro edificio de planta rectangular y la Iglesia de planta cruciforme inscrita en un rectángulo (OLMO ENCISO, 1995: 213-215), define el trazado urbanístico del resto de la ciudad y se comunica con esta a través de una puerta de la que arranca el eje viario más importante. Toda la ciudad está rodeada por una muralla jalonada por torres cuadrangulares y en las que se abren las puertas de acceso de las que hasta el momento se ha excavado una (OLMO ENCISO, 1995: 213). Las cerámicas de esta fase responden a tres tipos de producciones, finas, comunes y de cocina, con una mínima presencia residual de cerámicas a mano, junto con producciones de importación definidas por ánforas norteafricanas -fundamentalmente Keay LXII- así como spatia o anforiscos.

La fundación y primera fase de ocupación de Recópolis habría que ponerla en relación con el, ya citado, fenómeno de revitalización y dinamismo urbano en la segunda mitad del VI del que formarían parte los ejemplos debidos a la iniciativa eclesiástica anteriormente analizados así como la intervención de la monarquía visigoda en el planeamiento urbano a través de la fundación y mejora de ciudades. En este sentido conviene recordar como durante el reinado de Leovigildo, además de Recópolis, se funda en el 58 I la ciudad de Victoriaco, y se restauran en el 583 las murallas de Itálica, así mismo durante el reinado de Suintila se fundará la ciudad de Ologicus, con el trabajo y los tributos impuestos a los vascones. Toda esta política urbana del Estado visigodo, con la excepción de la rehabilitación de las murallas de Toledo por el rey Wamba, se realiza en un periodo de aproximadamente medio siglo comprendido entre el último cuarto del Vl y primer cuarto del VII, que corresponde a la fase de consolidación del Estado visigodo.

Por tanto, este fenomeno de revitalización urbana que se produce entre la segunda mitad del VI y principios del VII, nos está reflejando la importancia que la ciudad va a tener en la estructuración de la sociedad de la época, máxime cuando se comprueba cómo ésta va a ser protagonista de una parte importante del conflicto social que se desarrolla en ese periodo. De hecho el poder político y económico que la Iglesia católica poseía a mediados del siglo $\mathrm{VI}$, del que su política edilicia y de planeamiento urbano aquí tratada es un claro testimonio construcción, ampliación y mejora de conjuntos episcopales, construcción de edificios asistenciales, intervenciones urbanísticas..- suponía una amenaza para el intento de crear un Estado centralizado y controlado por la monarquía. Este Estado tratará de cohesionarse ideologicamente a traves de la proclamación del arrianismo como religión oficial que, como ya he expuesto, debe analizarse como un intento de mermar el poder de la iglesia católica así como posiblemente de asumir o controlar sus prerrogativas fiscales. Un buen ejemplo del éxito inicial del sistema fiscal del Estado en su fase fundacional lo ofrecerá su ya expuesta política urbana, principalmente la fundación de Recópolis y, en menor medida, la fundación de Victoriaco y la restauración de las murallas de Itálica. Tras el pacto entre el Estado y la Iglesia representado en el III Concilio de Toledo que, entre otras cosas, supondrá la aceptación por parte del primero de la participación de la Iglesia en la administración del Estado, todavía asistiremos a la continuidad por parte de la monarquía de una política de fundación de ciudades tal y como refleja la efectuada por Suintila en Ologicus.

Toda esta fase señala, por tanto, el carácter de la ciudad como centro de la estructuración territorial del reino de Toledo, basada en la interacción existente en el binomio ciudadterritorio (OLMO ENCISO, 1985-1991: 74-75). Las excavaciones de Recópolis muestran la relación de la ciudad con su territorio a través de la explotación de sus recursos. La presencia y consumo de ganado ovicaprino y bovino, uno de sus principales recursos, la explotación de recursos forestales destinados a la construcción, la caza, así como la propia explotación y transformación del paisaje desde el momento de la fundación de la ciudad, son testimonios bastante elocuentes, por ahora, de esta interacción (OLMO ENCISO, 1995: 211-212, 217). Sin embargo, es necesario definir mejor el nivel de la misma y, sobre todo, el grado de control y de articulación del territorio que se ejerce desde la ciudad. En este sentido, los grandes centros urbanos aquí analizados son los cen- 
tros económicos y bases del sistema fiscal tal y como demuestra el que todos ellos posean ceca. Esto es evidente en Recópolis con una ceca, la única junto con Toledo de toda la submeseta sur, que en esta fase, a tenor de los datos actuales, acuña moneda en época de Leovigildo y Recaredo. En el caso de esta ciudad la función administrativa, de la que tantas referencias nos ofrecen las fuentes escritas, está claramente expresada en el paisaje urbano a través del conjunto palatino, reflejo, igualmente, del funcionamiento del sistema tributario en esta primera fase del Estado visigodo. Sin embargo, una vez aceptado dicho funcionamiento es necesario definir su grado de coerción. Se puede apuntar en esta dirección defendiendo como punto de partida, que en este momento el grado de coerción que la ciudad, en este caso el Estado, ejerce sobre el territorio es menor que en otros periodos, tal y como ratifica la investigación arqueológica (OLMO ENCISO, 1995: 217). Si comparamos el "paisaje" de diferentes tipos de asentamientos, grandes ciudades como las aquí analizadas de Mérida y Recópolis, otros centros urbanos como el Tolmo de Minateda (GUTIERREZ LLORET, 1996), sitios como Arcávica (ALVAREZ DELGADO, 1989; BARROSO CABRERA, MORIN DE PABLOS, 1994) y los poblados de la cuenca hidrográfica del Tajo y del Sistema Central (CABALLERO, L., MEGIAS, G., 1977; CABALLERO ZOREDA, L, 1989; OLMO ENCISO, 1985(991), veremos que hay una mayor homogeneización de éste analizándolo desde una perspectiva diacrónica en relación con otros periodos. Por tanto, esta menor diferenciación observada nos está testimoniando, así mismo una menor capacidad de coerción por parte del Estado, y de la ciudad como centro articulador del territorio que necesariamente afecta al paisaje de la misma y posibilita una interpretación sobre la estructura social de la época (OLMO ENCISO, 1990-97: 267; 1992: 194; 1995: 217).

\section{La ciudad y la crisis del estado visigodo}

Al periodo de consolidación del Estado visigodo, durante la segunda mitad del VI y primeras décadas del VII, en el que se produce todo el analizado fenómeno de revitalización urbana, le sucederá un proceso de crisis que tendrá igualmente su reflejo en la ciudad. En este sentido cabe preguntarse acerca de las causas de la sensible disminución o cese de la actividad edilicia y urbanística en las ciudades de la segunda mitad del siglo VII. En lo referente a la actividad de la Iglesia esta se encuentra testimoniada por la escasez de testimonios escritos y arqueológicos de dicha actividad, a diferencia de lo que sucedía en el VI. El mismo fenómeno se observa en lo que concierne a la actividad edilicia del Estado, si exceptuamos la noticia sobre las obras de embellecimiento y restauración de las murallas efectuadas por Wamba en Toledo, en una época en la que ya alguna de estas ciudades, a tenor de lo que por el momento ofrecen Recópolis y Mérida, se encuentran en un proceso de desestructuración de la trama urbana.

En Recópolis la segunda fase de época visigoda nos documenta un proceso de alteración y pérdida de la trama urbana regular, así como de posible cambio en el conjunto palatino. Esta alteración viene definida por la ocupación de áreas públicas, cerramiento de espacios abiertos, y edificación en ellas de nuevas construcciones de inferior calidad, así como compartimentación de alguna de las edificaciones anteriores. En esta fase, según los resultados de las excavaciones recientes, se continúan ocupando los edificios del conjunto palatino. Sin embargo, los datos procedentes de las últimas campañas, apuntan a un proceso de cambio en la funcionalidad de, al menos, el edificio meridional de este conjunto, documentado por una fase de abandono del piso superior. El hecho de que los pisos superiores de estos edificios sean los de mayor calidad -pavimentos de opus signinum, presencia de decoración arquitectónica...-, y que su abandono esté relacionado con el proceso de alteración de la trama urbana, ofrece un testimonio relevante acerca de la transformacion de la ciudad en esta fase. Nos encontramos, por tanto, ante un fenómeno de desaparición o pérdida de gran parte de las funciones -administrativas y residenciales- para las que estos edificios fueron concebidos, fenómeno que forma parte del proceso de desestructuración urbana. Creo que este proceso debe relacionarse con la propia desestructuración y crisis del Estado visigodo que se 
acrecienta fundamentalmente en la segunda mitad del siglo VII. Sin embargo, en esta segunda fase hay que destacar la continuidad de las producciones cerámicas características de la anterior -finas, comunes y de cocina-, con una práctica ausencia de la cerámica a mano, así como de ánforas -Keay LXII- y anforiscos o spatia con una función ya de contenedores (OLMO ENCISO, 1995: 216).

Este paisaje urbano de la segunda fase será el que prácticamente defina la primera andalusí hasta su destrucción, entre fines del VIII principios del IX relacionada con las revueltas beréberes en esta zona, a la que seguirá una posterior ocupación dirigida a una explotación agrícola del terreno de la antigua ciudad, así como una ulterior utilización como cantera para la construcción de la andalusí Zorita, fases estas datadas en la primera mitad del IX (OLMO ENCISO, 1995: 216-217).

La mencionada crisis del Estado visigodo es el factor fundamental para analizar el proceso de decrecimiento de la actividad urbanística. De hecho los motivos que produjeron dicho proceso son diferentes, según estén relacionados con el Estado o la Iglesia, aunque insertos en el mismo proceso de transformación social.

En lo referente al Estado nos encontramos ante una estructura debilitada, con un sistema fiscal en crisis. Con esta situación habría que relacionar la transformación del conjunto palatino de Recópolis que muestra cómo esta crisis afecta en el paisaje urbano a los edificios definitorios de dicho Estado, a través del único ejemplo que, por el momento, poseemos de arquitectura civil.

Igualmente en este periodo decrecerá sensiblemente la actividad edilicia eclesiástica en las ciudades. Sin embargo, y a diferencia del Estado, la Iglesia gran propietaria de bienes y en parte animadora y beneficiaria de la crisis del sistema fiscal, continuará su actividad edilicia en el ámbito rural a través de la construcción de iglesias y monasterios. En dicha actividad conectará en este caso con la desarrollada por la aristocracia fundiaria, buen ejemplo de lo cual lo ofrece la villa de Pla del Nadal JUAN, PAS-
TOR: 1989). Este abandono de la actividad edilicia urbana en beneficio de la rural, constituye una muestra de como la Iglesia participa en la defensa de un modelo de sociedad feudal a diferencia de su posición en la fase anterior.

Por tanto, el proceso de transformación que se desarrolla en gran parte del siglo VII y que finalmente supondrá el paso a una situación de predominio de una sociedad feudal, se verá claramente reflejado en la ciudad tal y como ejemplifican los casos aquí citados. El debilitamiento del sistema fiscal visigodo afectará de forma determinante al paisaje urbano con la consiguiente crisis de la actividad edilicia por parte del Estado y de la Iglesia, acompañada de procesos de desestructuración urbana documentados en algunas ciudades de este periodo. Todo este proceso hasta aquí analizado nos proporciona claros ejemplos que vienen a reforzar la idea de cómo los procesos de feudalización son opuestos al desarrollo urbano (WICKHAM, 1984).

Todo lo hasta aquí analizado refleja un proceso de transformación urbana que, por el momento, parece afectar a grandes ciudades con una evidente función de centros administrativos, fiscales y económicos. Sin embargo, la realidad urbana de la península no sólo está definida por este tipo de ciudades, ya que los ejemplos de otras, apuntan a un fenómeno urbano no homogéneo y que, en algunos de estos centros, va a estar definido por las características culturales y socioeconómicas del territorio en que se sitúan. El hecho de que esta crisis no afecte de forma tan determinante, a otros centros urbanos que presentan una solución de continuidad en su paisaje urbano hasta el siglo IX, y en los que se produce una mayor integración de éstos y el ámbito rural (GUTIERREZ LLORET, 1996) O, por el contrario, la constatación de cómo algunas ciudades desaparecen en esta segunda fase, siendo sustituidas por otros centros urbanos próximos, como en el caso del Alto Guadalquivir (CASTILLO ARMENTEROS, 1998: 164), son factores que vendrían a demostrar lo expresado al principio de este trabajo sobre la necesidad de analizar el tema de la ciudad desde la perspectiva de las dinámicas sociales que en ella se desarrollan, así 
como desde la necesidad de abordar este análisis atendiendo a las características del territorio en que se encuentran estas ciudades (OLMO ENCISO, 1990-1997: 265).

\section{BIBLIOGRAFIA:}

A.A.V.V., (1990): L' Amfiteatre Romà de Tarragona, La Basílica Visigòtica i l' Església Romànica, Memòries d' Excavació, TED`A, Tarragona.

ALBA CALZADO, M., (1997): "Ocupación diacrónica del área arqueológica de Morería (Mérida)", Mérida. Excavaciones arqueológicas, 1994-1995, Mérida, pp. 285-316.

ALVAREZ DELGADO, Y., (1989): "Cerámicas del siglo IX de Arcávica (Cuenca)", Boletín de Arqueología Medieval, n 3, Madrid, pp. 109-121.

BARROSO CABRERA, R., MORIN DE PABLOS, J., (1994): "La ciudad de Arcávica en época visigoda: Fuentes literarias y testimonios arqueológicos", $1{ }^{\circ}$ Congresso de Arqueología Peninsular, vol. 34, Porto.

CABALLERO, L., MEGIAS, G., (1977): "Informe de las excavaciones del poblado medieval del Cancho del Confesionario, Manzanares el Real (Madrid), Noticiario Arqueológico Hispánico, 5, Madrid, pp. 325-332.

CABALLERO ZOREDA, L., (1989): "Cerámicas de época visigoda y postvisigoda de las provincias de Cáceres, Madrid y Segovia", Boletín de Arqueología Medieval, n 3, Madrid, pp. 75- 107.

CABALLERO ZOREDA, L., MATEOS, P., (1992): "Trabajos arqueológicos en la Iglesia de Santa Eulalia de Mérida", Jornadas sobre Sta. Eulalia de Mérida, Mérida, pp. I550.

CAMPOS, J., (1960): Juan de Biclaro, obispo de Gerona. Su vida y su obra, Madrid.

CASTILLO ARMENTEROS, J.C. (1998): La campiña de Jaén en época emiral (s. VIII-X), Jaén.

GARCIA MORENO, L.A. (1993), "La ciudad visigoda", en, M.J. Ferro Tavares (ed.), A Cidade, Lisboa.

GRANADOS, J.O., (1995): "Notes per a l'estudi de la basilica i del conjunt episcopal paleocristià de Barcelona. Valoració de la primera fase", IV Reunió d' Arqueologia Cristiana Hispánica, Lisboa 1992, Barcelona, pp. 121-131.

GUTIERREZ LLORET, S. (1993): "De la civitas a la madina: destrucción de la ciudad en el sureste de Al-Andalus. El debate arqueológico", IV Congreso de Arqueología Medieval Española, Alicante 1993, t. I, Alicante, pp. 13-36.
(1996): La Cora de Tudmir de la Antiguedad Tardía al Mundo Islámico. Poblamiento y Cultura Material, Madrid-Alicante.

JUAN, E., PASTOR, I., (1989): "Los visigodos en Valencia. Pla de Nadal iuna villa áulica?", Boletín de Arqueología Medieval, n³ 3, Madrid, pp. 137-180.

MATEOS CRUZ, P., ( 1992), "El culto a Santa Eulalia y su influencia en el urbanismo emeritense (siglos IV-VI)", Jornadas sobre Sta. Eulalia de Mérida, Mérida, pp. 57-79.

OLMO ENCISO, L., (|985-199|): "La ciudad de Recópolis y el habitat en la zona central de la península ibérica durante la época visigoda", Gallo-romains, Wisigoths et Francs en Aquitaine, Septimanie et Espagne, Actes de VII Journées Internationales d`Archeologie Mérovingienne, Tolouse, 1985, Rouen 1991, pp. 71-82.

(|99|): "Ideología y Arqueología: los estudios sobre el periodo visigodo en la primera mitad del siglo XX", en ARCE, J., OLMOS, R. (eds.) Historiografía de la Arqueología y la Historia Antigua en España (Siglos XVIII-XX), Madrid, pp. I57-I60.

(1992): "El reino visigodo de Toledo y los territorios bizantinos. Datos sobre la heterogeneidad de la península ibérica durante la época visigoda", Coloquio Hispano-Italiano de Arqueología Medieval, Granada, pp. 185-198.

(1995): "Proyecto Recópolis: ciudad y territorio en época visigoda", Arqueología en Guadalajara, Patrimonio Histórico-Arqueología Castilla-La Mancha, $\mathrm{n}^{\circ} 12$, Toledo, pp. 21 I-223.

(1990-97): "Nuevas perspectivas para el estudio de la ciudad en la época visigoda", Los visigodos y su mundo, Jornadas Internacionales, Ateneo de Madrid, noviembre 1990, número monográfico de Arqueología, Paleontología y Etnografia, 4, Madrid 1997, pp. 26I-269.

OLMO ENCISO, L., MENASANCH, M., (1993): "El poblamiento tardorromano y altomedieval en la cuenca baja del río Almanzora (Almería)", Investigaciones Arqueológicas en Andalucía, 1985-1992. Proyectos, Huelva, pp. 675-680.

SORIANO SANCHEZ, R., (1995): "Los restos arqueológicos de la sede episopal valentina. Avance preliminar", IV Reunió d' Arqueologia Cristiana Hispánica, Lisboa 1992, Barcelona, pp. 133-140.

VIVES, J. (1969): Inscripciones cristianas de la España romana y visigoda, CSIC, Barcelona.

WHITTOW, M., (1990), "Ruling the Late Roman City and Early Byzantine City: A Continuous History", Past and Present, 129, pp. 3-29.

WICKHAM, C. (1984), "The Other Transition: From the Ancient World to Feudalism", Past and Present $n^{\circ} 103$, pp.3-36, Oxford. 


\section{RESUMEN}

Esta artículo parte de un concepto de ciudad, no estática ni homogénea, sometida a unas dinámicas de transformación que reflejan el proceso que se desarrolla en la estructura social de la época. A partir de las recientes excavaciones en algunos de los grandes centros urbanos, se defiende la existencia de dos fases que los caracterizan. La primera de éstas -segunda mitad del s. VI, primeras décadas del s. VII- refleja un renacimiento de la importancia de la ciudad, mientras que la segunda fase -segunda mitad del s. VIIdocumenta un fenómeno de desestructuración de la trama urbana que debe conectarse con la crisis del Estado Visigodo

PALABRAS CLAVE: Época visigoda, Estado, ciudad, urbanismo, dinámicas sociales

\section{ABSTRACT}

The methods used for reconstructing the picture of This paper supports a conception of town, based on dynamics of transformation reflecting the process developped in the social structure of the period. Following the recent archaeological research it states the existence of two phases. The first phase -second half of the 6th century and early decades of the 7threflects a rebirth of some of the towns. The second phase -second half of the 7th century- shows an urban de-structuration connected with the crisis of Visigothic State.

KEY WORDS: Visigothic period, State, town, town planning, social dynamics. 